International Journal of Advanced Trends in Computer Science and Engineering

Available Online at http://www.warse.org/IJATCSE/static/pdf/file/ijatcse11832019.pdf

https://doi.org/10.30534/ijatcse/2019/11832019

\title{
Examining the Use of Geographical Information System (GIS) on the Cadastral Data Study
}

\author{
Norriza Hussin $^{1}$, WEINING LI ${ }^{2}$ \\ ${ }^{1}$ Senior Lecturer, School of Information Technology, SEGi University. Petaling Jaya, Selangor, Malaysia, \\ norriza@ segi.edu.my. \\ ${ }^{2}$ Lecturer, Faculty of Civil and Surveying Engineering, Guiling University of Technology at Nanning, China \\ School of Information Technology, SEGi University. Petaling Jaya, Selangor, Malaysia.
} 372781572@qq.com.

\begin{abstract}
From the perspective of system design and development, this paper combines GIS and cadastral management to analyze and study the system, and expounds the overall design, functional design and database design of the system. This paper introduces the design principles, system goals and system structure of the system. From the perspective of functional design it introduces the function of the system. From the perspective of database structure, the storage methods of different data in the system are introduced. Finally, this paper puts forward the views on the construction and development of the system.
\end{abstract}

Key words: Cadastral data, GIS, MIS

\section{INTRODUCTION}

With the development of the national economy and the implementation of land-paid legislation, the workload of cadastral changes is increasing, and the concept of "digital territory" is gradually gaining popularity among people. There are some concerns to be highlighted, such as frequent real estate transactions, land confirmation, land dispute and so on. These aspects motivate the authors to acquire some information such as situations or changes of a parcel or a certain area during a certain period exactly. The challenge on massive cadastral management information and daily change data, traditional methods such as manual management cannot fulfill requirements of users, to implement the information management of land resources has become an inevitable trend [1]. Cadastral management is the core of land resource business, so the modernization of cadastral management is imperative.

Cadastre is a book that records the basic information of parcel such as land location, boundary, quantity, quality, ownership, and use (land type). Cadastral management is a national measure that obtains cadastral information to study land ownership, natural conditions and economic conditions. It adopts cadastral survey (measurement), land registration, land statistics, land evaluation and land economic evaluation to collect data and provide service. Parcels are the basic unit in cadastral management, which consist of boundary point and boundary line. The essential of cadastral management is parcel management. Cadastral management information system, which is a part of the category of geographic information systems, it is an information system that realizes the data input, storage, retrieval, processing, comprehensive analysis, auxiliary decision-making and result output of cadastral information with the support of computer and modern information technology, and with parcels (or plots) as the research objects. On the other hand, it is a land information system that adopts parcels/plots as a basic spatial information carrier, and is a specific application of GIS in the field of cadastral management. This research adopts cadastral data as the objects, and tries to establish an information system to be implemented orderly and efficient management and use of data.

\section{DEMAND ANALYSIS}

The main work of cadastral information management includes cadastral survey, land statistics, land grading, land registration, and cadastral file management [2]. Cadastral data has the characteristics of large amount of data, frequent changes, and a wide variety.

According to the content of cadastral information management work, the cadastral management information system (CMIS) needs functions such as data query, statistics, editing and updating of graphic attribute data, spatial analysis, map creation, and statistical chart output. In addition, under the premise the daily cadastral information management, the interface of system needs to be easy to operate. It can reduce the difficulty of usage and also reduce costs of system establishment [3]. 


\section{KEY TECHNOLOGY}

This system uses Arc engine for secondary development. Arc engine is a component of GIS technology and a programming environment. It provides a library of components. Developers can use libraries and tools to create custom GIS desktop programs. The Arc engine consists of two parts, one is running the runtime; the other is the software development kit. There are many class libraries in Arc engine that are used to manage COM objects[3].

This system uses geodatabase to store and manage the cadastral data. The geodatabase is a new object-oriented spatial data model and data is stored in feature classes, object classes, and data sets. The object-oriented data model has a good effect on the representation of the objective world and the query of the attribute information.

\section{OVERALL DESIGN OF SYSTEM}

The overall structure of the system is shown in figure 1 .

\subsection{System design principle}

(1) Practicality. The system should meet the principle such as friendly interface, simple operation and easy to use.

(2) Openness. The system should use an open architecture, which can implement multi-platform data transfer-exchange and external user access.

(3) Scalability. The system can be executed system upgrade operations such as function addition and database upgrade according to actual work needs.

(4) Newest. The system must provide convenient and fast data maintenance and update functions, which can ensure the latest of the database.

( 5 ) Safety. The system can realize data storage and confidentiality, and intercept illegal access and data backup and recovery functions [3].

\subsection{System aims}

The components of GIS technology, such as the database management technology and computer network technology, facilitate this system on the structured programming method, and implements some functions such as data collection, data processing, data storage and management, data statistics and calculation, and output of results. According to the center of the work of land management there are some aims that the system should achieve as follow [4]. 1) Import of measurement data and ownership survey data. 2) Real-time update of data and to meet the needs of data statistics and graph changes. 3) Meet the requirements of the work and improve work efficiency. 4) Graphic data can be transferred in and out. 5) Massive data storage and query.

\subsection{System structure}

The system contains software and hardware, database and its application subsystem. Software and hardware are the material basis of the system, the physical structure. Database includes spatial database and attribute database. Application subsystem uses the database as the operation object to realize the functions of data retrieval, query, statistics, analysis, etc. to meet the needs of managing and applying cadastral information [5].

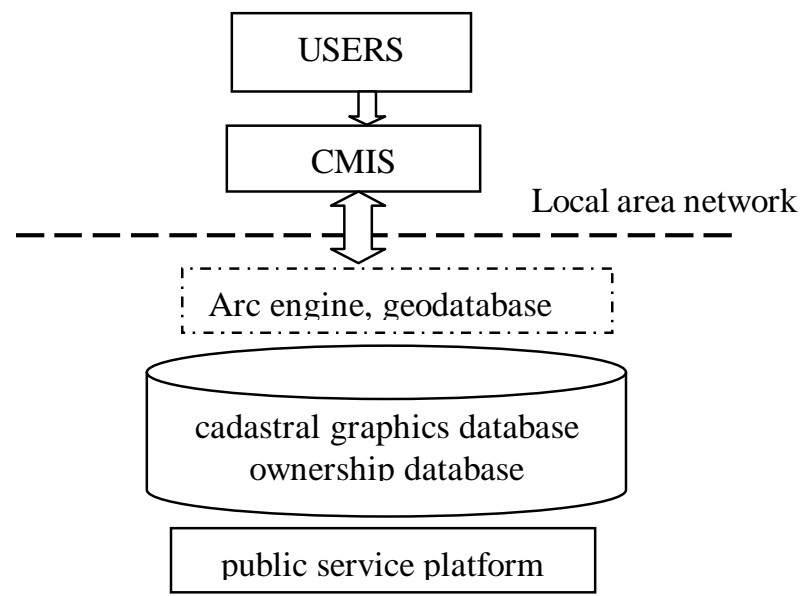

Figure 1: The Structure of System

\subsection{System functions}

According to functions, the cadastral management information system is divided into cadastral survey subsystem, land registration subsystem and system maintenance subsystem.

The cadastral survey subsystem includes two modules: cadastral graphics processing and ownership survey. Cadastral graphics processing consists of the coordinate transformation, editing, and topological relationship establishment of parcel graphics. It contains three parts: data input, processing, and output. The input of data refers to the acquisition of parcel graphic data through the interface input system. Data processing refers to data conversion and coordinate conversion of different formats and editing of graphic data into complete parcel map. Data output refers to the system outputting data in unformatted format, as well as output map and boundary coordinate table, etc. The ownership survey is a compilation of the data that formed by the investigation of the field survey into a survey form and the formation of a parcel boundary.

The land registration subsystem contains three modules, there are land registration, inquiry and statistics, and the form of the certificate. The land registration module is mainly to generate corresponding forms and sign the review opinions of each link according to the process of land registration type. The query and statistics module is a query for various data in the entire system based on user permissions, which consists of mutual check of graphics and attributes, registration status in business processing and query of historical files and print statistics and summary form. The form of the certificate prints out the completed approval form, land registration card, land certificate and other forms.

The system maintenance subsystem consists of user permission settings, workflow settings, data dictionary configuration, and data backup modules. Due to the 
Confidentiality and authority of cadastral data, user permission settings are also one of the security settings for system data. In order to safeguard the legitimate rights and interests of right holders and ensure the rigorous cadastral data and the rigor of approval, system data cannot be modified at will. According to different user settings, this module is to set different usage rights and different access and modify permissions. The workflow setting is flexible and can set different review links according to different types of land registration. The data dictionary setting is based on the hierarchy and coding of the system database, and can customize the data dictionary based on the original data dictionary. Data backup is the real-time backup and manual backup of data in the database, it is an important measure to ensure the data security of cadastral management information system.

\section{DATABASE DESIGN}

Cadastral database consists of two parts [6]: cadastral graphics database and ownership database. Graphics database includes cadastral map and parcel map, and ownership data includes cadastral survey, land registration, cadastral survey collected data, such as parcels, boundary point, attribute data. Cadastral graphics database and ownership database are connected with some key words such as ID or name.

\subsection{Storage structure of spatial data}

The spatial data of this system is divided into two major parts, one is terrain information, and the other is cadastral information. The classification of the terrain information adopts the national standard classification coding standard and has been expanded. The coding standard of cadastral information adopts the trial standard of the Ministry of Land and Resources in china. All data are stored in the database and each type of element is stored in a table, in order to save storage spaces, the terrain elements need to be integrated. Except for commonly used and large-volume elements such as houses, elevation points, contours, etc., which are stored in separate feature tables, all other data are basically summarized into point features, line features, polygon features, and composite element, for the marks of this system, there are contain description marks, administrative district marks and nature marks.

\subsection{Storage structure of ownership data}

The ownership data is mainly composed of the following parts. Parcel code, area, use, ownership property, classification, and these are stored in parcel table. Attributes of boundary point which are consists of point number, coordinates and category, are stored in boundary point table. Owner table which stores the information of parcel owner, for example name, ID, address, phone number and etc. Other rights table that stores other rights such as mortgage of parcel, rental of parcel.

\section{CONCLUSION}

This paper explains the research of cadastral information management system, uses Arc engine and c\# as development tools establish a file geodatabase in geodatabase, reduces development costs, and adopts $\mathrm{C} / \mathrm{S}$ mode to realize the development of digital cadastral management system. The main results are as follows: 1) Analyze the needs of the cadastral information management system, and explain the key technologies and characteristics of the implementation system. 2) The overall design of the cadastral information management system, including the system design principles, the development environment architecture, and the database. Design and function design. 3) Cadastral information management system stores the attribute data and vector data of the cadastral data. The functions of the system combine the characteristics of the cadastral data, such as data, layer management, query function, editing function, statistics, the output of the form, etc. The interface of system is clear, the operation is simple, and can meet the needs of daily cadastral information management. In the future, the use of big data will certainly help the management of cadastral data [7].

\section{ACKNOWLEDGEMENT}

The corresponding author LI WEINING would like to acknowledge the contributions from the members of research project named" Guangxi young and middle-aged teachers' basic ability upgrading project (2017KY0242)". Their hard work has helped a lot in writing this paper.

\section{REFERENCES}

1. ZHOU Xiaogaung, CHEN Jun. Geographic information world. GIS overview, Vol. 2, pp. 35-38, June 2006.

2. ZHU Dehai. Land management information system. Beijing: China Agricultural University Press, 2002, pp. 238-260.

3. ZHANG Fan, WANG Chongchang. Based on C/S Mode Design and Implementation of Network Town Cadastral Information System. Geomatics \& Spatial information technology, Vol. 8, pp.104-106, July 2017.

4. LIU Junhai. Development Status of Foreign Land Information System Construction. Land and Resources Information, Vol. 1, pp. 14-18, October 2001,

5. CHEN Jun, ZHOU Xing. Progress of Land Information System: Review of the Literature from 1997-1998. Chinese Land Science, Vol. 3, pp. 37-44, April 1999.

6. He Zongyi, Yang Ming, Chen Jianghua. Design and Development of Urban Cadastral Information. System Journal of Kunming University of Science and Technology: Science and Engineering Edition, Vol. 28, pp. 4-7, March 2003.

7. B.Manoj, K.V.K.Sasikanth. Analysis of Data Science with the use of Big Data. International Journal of Advanced Trends in Computer Science and Engineering, Vol. 7, NO. 6, pp. 87-90, November - December 2018. https://doi.org/10.30534/ijatcse/2018/02762018 